Pacific Journal of Mathematics

REMARK ON MAPPINGS NOT RAISING DIMENSION O 


\section{REMARK ON MAPPINGS NOT RAISING DIMENSION OF CURVES}

\section{J. KRASINKIEWICZ}

The purpose of this note is to prove three theorems on dimension raising ability of certain classes of maps defined on 1-dimensional continua. In particular we obtain a generalization of a recent result of J. Jobe concerning dimension raising ability of inverse arc functions defined on dendrites.

By a continuum we mean a compact connected metric space. A 1-dimensional continuum is called a curve. If each point of a continuum $X$ has arbitrary small neighborhood with finite boundary, then $X$ is said to be regular. $X$ is suslinian provided any collection of mutually disjoint nondegenerate subcontinua of $X$ is at most countable [6]. For a nondegenerate continuum we have the following implications:

(i) (regular) $\Rightarrow$ (suslinian) $\Rightarrow$ (1-dimensional).

Let $f$ be a mapping of a continuum $X$ into a continuum $Y$. We shall consider the following properties of $f$ :

$(\alpha)$ for every arc $L \subset Y$ there exists an arc $M \subset X$ which is mapped by $f$ onto $L$, i.e., $f(M)=L$.

( $\beta$ ) for every arc $L \subset Y$ there exists a continuum $M \subset X$ which is mapped by $f$ onto $L$.

( $\gamma$ ) for every continuum $L \subset Y$ there exists a continuum $M \subset X$ which is mapped by $f$ onto $L$.

THEOREM 1. If $f$ is a mapping with property $(\beta)$ of a suslinian continuum $X$ onto a locally connected continuum $Y$, then $Y$ is suslinian.

Proof. Suppose it is not true. Then there is an uncountable collection $\{B\}$ of nondegenerate mutually disjoint subcontinua of $Y$. Consider a member $B \in\{B\}$. Let $a$ and $b$ be distinct points of $B$. Let $U_{1}, U_{2}, \cdots$ be a decreasing sequence of neighborhoods of $B$ (in $Y$ ) which limits on $B$, i.e.,

$$
\bigcap_{n} U_{n}=B
$$

For each positive integer $n$ there is a locally connected continuum $C_{n}$ such that

$$
B \subset C_{n} \subset U_{n} \quad \text { (see [5], p. 260) }
$$


Let $L_{n}$ be an arc in $C_{n}$ joining $a$ and $b$. We may assume that $\left\{L_{n}\right\}$ is a convergent sequence (otherwise we take a convergent subsequence). Let $B^{\prime}$ denote the limit of this sequence. Hence by (1) and (2) we have

(3) $B^{\prime}$ is a nondegenerate subcontinuum of $B$ (because $a, b \in B^{\prime}$ ).

For each integer $n$ there is a continuum $A_{n} \subset X$ which is mapped by $f$ onto $L_{n}$. Choose a convergent subsequence of $\left\{A_{n}\right\}$ and let $A_{B}$ be its limit. It is clear that

$$
f\left(A_{B}\right)=B^{\prime} .
$$

According to (3) and (4) we see that for each $B \in\{B\}$ we can construct a nondegenerate continuum $A_{B} \subset X$ which is mapped by $f$ onto a subcontinuum of $B$. It follows that $\left\{A_{B}: B \in\{B\}\right\}$ constitute an uncountable collection of nondegenerate mutually disjoint subcontinua of $X$, contrary to our assumption on $X$. This proves the theorem.

Mappings with property $(\alpha)$ were considered by J. Jobe in [3] (where they are called inverse arc functions). There was shown that if $f$ is a mapping with property $(\alpha)$ from a dendrite $X$ with countably number of endpoints onto $Y$, then $\operatorname{dim} Y \leqq 1$ (dendrite = locally connected continuum containing no simple closed curve). J. Jobe asks if the above result can be extended onto all dendrites. Since $(\alpha) \Rightarrow(\beta)$, then the following corollary to Theorem 1 answers this question in the affirmative.

CoRollary. If $f$ is a mapping with property $(\beta)$ defined on a dendrite $X$, then $f(X)$ is at most 1-dimensional.

Proof. Clearly, $f(X)$ is a locally connected continuum. Since each dendrite is regular ([5], p. 301), the corollary is an immediate consequence of (i) and Theorem 1.

We are now going to prove two theorems related to the above corollary.

Let $D$ be the unit disk in the complex plane and let $S$ denote the boundary of $D$. A mapping $f: X \rightarrow D$ is called essential in the sense of Alexandroff-Hopff, briefly: $A H$-essential, provided the partial mapping

$$
f \mid f^{-1}(S): f^{-1}(S) \longrightarrow S
$$

can not be extended onto $X$. It is known that

(ii) If $X$ is compact and $\operatorname{dim} X \geqq 2$, then there exists an $A H$ essential map of $X$ onto $D$ (see [7]). 
By a classical result of Mazurkiewicz [7] we have

(iii) An $A H$-essential map has property ( $\gamma$ ).

A space $X$ is said to be contractible with respect to $S$, briefly: cr $S$, if each map $f: X \rightarrow S$ is nullhomotopic. It is well known that

(iv) Each closed subset of a cr $S$ curve is cr $S$ ([2], p. 83).

It has been proved by M. K. Fort, Jr. [1] that there exists a continuum $K \subset D$ such that

(v) No continuum er $S$ can be mapped onto $K$.

Using these facts we shall prove the following

THEOREM 2. If $X$ is a cr $S$ curve and $f: X \rightarrow Y$ has property $(\gamma)$, then $\operatorname{dim} Y \leqq 1$.

Proof. Suppose $\operatorname{dim} Y \geqq 2$. Hence by (ii) there is an $A H$-essential map $g: Y \rightarrow D$. Since the composition of two maps having property $(\gamma)$ is a map with property $(\gamma)$, then by (iii) the map $h=g f$ has property $(\gamma)$. Let $K \subset D$ be the Fort continuum. There exists a continuum $L \subset X$ such that $h(L)=K$. By (iv), $L$ is cr $S$. Hence $K$ can be obtained as a continuous image of a cr $S$ continuum, contrary to (v). This contradiction completes the proof.

A continuum $X$ is tree-like if for each $\varepsilon>0$ there exist a finite tree $T$ and a continuous map $f: X \rightarrow T$ onto $T$ such that $\operatorname{diam} f^{-1}(t)<\varepsilon$ for every $t \in T$. It is known that every tree-like continuum is $\mathrm{cr} S$. Recently the author has proved that if $Y$ is a cr $S$ curve and if there exists a tree-like curve which can be mapped onto $Y$, then $Y$ is tree-like [4]. Combining these results with Theorem 2 we obtain

THEOREM 3. Let $f$ be a mapping from a tree-like curve onto a continuum $Y$. If $f$ has property $(\gamma)$ and $Y$ is or $S$, then $Y$ is treelike.

\section{REFERENCES}

1. M. K. Fort, Jr., Images of plane continua, Amer. J. Math., 81 (1959), 541-546.

2. W. Hurewicz and H. Wallman, Dimension Theory, Princeton, 1948.

3. J. Jobe, Dendrites, dimension, and the inverse arc function, Pacific J. Math., 45 (1973), 245-256.

4. J. Krasinkiewicz, Curves which are continuous images of tree-like continua are movable, Fund. Math., (to appear).

5. K. Kuratowski, Topology, vol. 2, Warsaw-New York, 1968.

6. A. Lelek, On the topology of curves II, Fund. Math., 70 (1971), 131-138.

7. S. Mazurkiewicz, Sur l'existence des continus indećomposables, Fund. Math., 25 (1935), 327-328.

Received January 10, 1974 and in revised form September 18, 1974.

Polish Academy of Sciences 



\section{PACIFIC JOURNAL OF MATHEMATICS}

\section{EDITORS}

RICHARD ARENS (Managing Editor)

University of California

Los Angeles, California 90024

\section{R. A. Beaumont \\ University of Washington \\ Seattle, Washington 98105}

\section{J. DugundJI}

Department of Mathematics

University of Southern California

Los Angeles, California 90007

D. Gilbarg and J. Milgram

Stanford University

Stanford, California 94305

\section{ASSOCIATE EDITORS}
E. F. BECKENBACH
B. H. NeumanN
F. WOLF
K. YOSHIDA

\section{SUPPORTING INSTITUTIONS}

UNIVERSITY OF BRITISH COLUMBIA
CALIFORNIA INSTITUTE OF TECHNOLOGY
UNIVERSITY OF CALIFORNIA
MONTANA STATE UNIVERSITY
UNIVERSITY OF NEVADA
NEW MEXICO STATE UNIVERSITY
OREGON STATE UNIVERSITY
UNIVERSITY OF OREGON
OSAKA UNIVERSITY

UNIVERSITY OF BRITISH COLUMBIA

UNIVERSITY OF CALIFORNIA

MONTANA STATE UNIVERSITY

NEW MEXICO STATE UNIVERSITY

OREGON STATE UNIVERSITY

OSAKA UNIVERSITY

\author{
UNIVERSITY OF SOUTHERN CALIFORNIA \\ STANFORD UNIVERSITY \\ UNIVERSITY OF TOKYO \\ UNIVERSITY OF UTAH \\ WASHINGTON STATE UNIVERSITY \\ UNIVERSITY OF WASHINGTON \\ AMERICAN MATHEMATICAL SOCIETY \\ NAVAL WEAPONS CENTER
}

The Supporting Institutions listed above contribute to the cost of publication of this Journal, but they are not owners or publishers and have no responsibility for its content or policies.

Mathematical papers intended for publication in the Pacific Journal of Mathematics should be in typed form or offset-reproduced, (not dittoed), double spaced with large margins. Underline Greek letters in red, German in green, and script in blue. The first paragraph or two must be capable of being used separately as a synopsis of the entire paper. Items of the bibliography should not be cited there unless absolutely necessary, in which case they must be identified by author and Journal, rather than by item number. Manuscripts, in triplicate, may be sent to any one of the editors. Please classify according to the scheme of Math. Reviews, Index to Vol. 39. All other communications should be addressed to the managing editor, or Elaine Barth, University of California, Los Angeles, California, 90024.

The Pacific Journal of Mathematics expects the author's institution to pay page charges, and reserves the right to delay publication for nonpayment of charges in case of financial emergency.

100 reprints are provided free for each article, only if page charges have been substantially paid. Additional copies may be obtained at cost in multiples of 50 .

The Pacific Journal of Mathematics is issued monthly as of January 1966. Regular subscription rate: $\$ 72.00$ a year (6 Vols., 12 issues). Special rate: $\$ 36.00$ a year to individual members of supporting institutions.

Subscriptions, orders for back numbers, and changes of address should be sent to Pacific Journal of Mathematics, 103 Highland Boulevard, Berkeley, California, 94708.

PUBLISHED BY PACIFIC JOURNAL OF MATHEMATICS, A NON-PROFIT CORPORATION

Printed at Kokusai Bunken Insatsusha (International Academic Printing Co., Ltd.), 270, 3-chome Totsuka-cho, Shinjuku-ku, Tokyo 160, Japan.

Copyright (C) 1973 by Pacific Journal of Mathematics Manufactured and first issued in Japan 


\section{Pacific Journal of Mathematics \\ Vol. 55, No. $2 \quad$ October, 1974}

Walter Allegretto, On the equivalence of two types of oscillation for elliptic

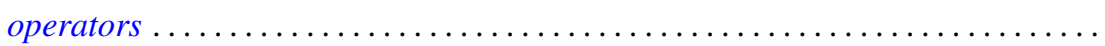

Edward Arthur Bertram, A density theorem on the number of conjugacy classes in

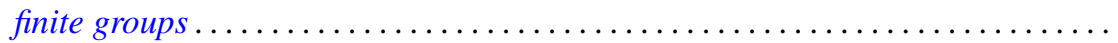

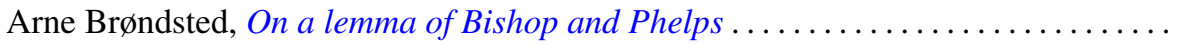

Jacob Burbea, Total positivity and reproducing kernels ..................

Ed Dubinsky, Linear Pincherle sequences . . . . . . . . . . . . . . . . . .

Benny Dan Evans, Cyclic amalgamations of residually finite groups .............

361

Barry J. Gardner and Patrick Noble Stewart, A "going down" theorem for certain

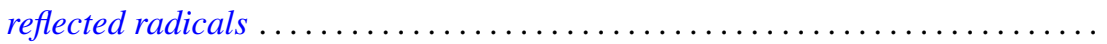

381

Jonathan Light Gross and Thomas William Tucker, Quotients of complete graphs:

revisiting the Heawood map-coloring problem ....................

Sav Roman Harasymiv, Groups of matrices acting on distribution spaces .........

Robert Winship Heath and David John Lutzer, Dugundji extension theorems for

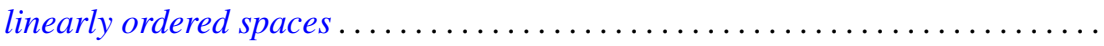

Chung-Wu Ho, Deforming p. l. homeomorphisms on a convex polygonal

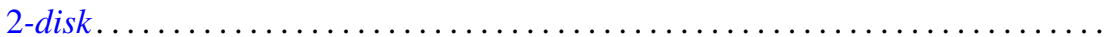

Richard Earl Hodel, Metrizability of topological spaces .................

Wilfried Imrich and Mark E. Watkins, On graphical regular representations of

cyclic extensions of groups .......................... 461

Jozef Krasinkiewicz, Remark on mappings not raising dimension of curves ..... . 479

Melven Robert Krom, Infinite games and special Baire space extensions . . . . . . 483

S. Leela, Stability of measure differential equations . . . . . . . . . . . . . . . . 489

M. H. Lim, Linear transformations on symmetric spaces . . . . . . . . . . . . . . . 499

Teng-Sun Liu, Arnoud C. M. van Rooij and Ju-Kwei Wang, On some group algebra modules related to Wiener's algebra $M_{1} \ldots \ldots \ldots \ldots \ldots \ldots \ldots \ldots \ldots \ldots \ldots$

Dale Wayne Myers, The back-and-forth isomorphism construction ............ 521

Donovan Harold Van Osdol, Extensions of sheaves of commutative algebras by

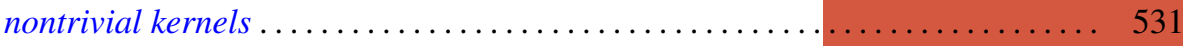

Alan Rahilly, Generalized Hall planes of even order ................... 543

Joylyn Newberry Reed, On completeness and semicompleteness of first countable

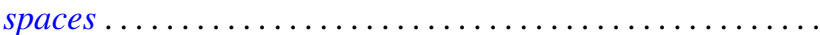

Alan Schwartz, Generalized convolutions and positive definite functions associated

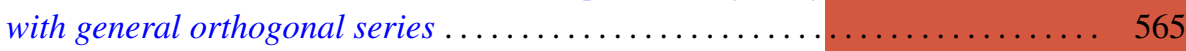

Thomas Jerome Scott, Monotonic permutations of chains . . . . . . . . . . . 583

Eivind Stensholt, An application of Steinberg's construction of twisted groups .... 595

Yasuji Takeuchi, On strongly radicial extensions . . . . ................. 619

William P. Ziemer, Some remarks on harmonic measure in space . . . . . . . . . . 629

John Grant, Corrections to: “Automorphisms definable by formulas” . . . . . . . . 639

Peter Michael Rosenthal, Corrections to: "On an inversion for the general

Mehler-Fock transform pair" ......................... 640

Carl Clifton Faith, Corrections to: "When are proper cyclics injective” . . . . . . 640 